\title{
IN DEFENSE OF AN UNSYSTEMATIC SCIENCE OF LAW
}

\section{MAX RADIN†}

A GROUP of sixteen persons were indiscreet enough to yield to the honeyed persuasion of an eminent exponent of legal philosophy and to contribute to a symposium called "My Philosophy of Law". When the book was published the title set in active motion all the obscure complexes of three types of lawyers. The first included those who felt it their duty to echo Dicey's peevish and unhistorical statement that legal philosophy stank in the nostrils of common lawyers. The second was made up of persons who feared that the wide use of philosophical methods and ideas in law would compel them to think about the meaning and function of the terms with which they dealt. And the third type contained those many persons to whom philosophy is a kind of secluded Elysium in which they hope to spend their days of contemplative retirement when they have got rid completely of such sordid and mundane things as Lawrence v. Fox and Pcnnoyer z. Neff. All these types are represented in the reviews of the regrettably indiscreet volume already mentioned, and often in the same reviewer.

It is gratifying that some at least of the gentlemen who undertook to review the book were sufficiently free from these glandular disturbances to get the idea that to state "a philosophy of law" was neither wickedly presumptuous nor a silly waste of time nor un-American or un-English. Speaking for one sixteenth of the authorship of the book, I can only say that by "philosophy of law" - an abhorrent term that should be discarded - I had nothing more pretentious in mind than an attempt to set forth in order certain general considerations, supplementing and illustrating notions about the law which I have expressed in one form and another for many years, most recently in the Storrs lectures at Yale University in 1940, afterwards published as "Law as Logic and Experience".2

In that book, as elsewhere, I presented doctrines about law - I deliberately do not say a doctrine - which, after examining a number of the criticisms of the book as they appeared in reviews, I find no compelling reason to abandon. Doubtless my presentation might well have

$\uparrow$ Professor of Law, University of California School of Jurisprudence.

1. My Prinosophy of LAw. Published under the direction of the Julius Resenvald Foundation, Northwestern University. Boston, 1941.

2. The book has been very widely reviewed both in legal and other periodicals. Most of the reviewers have been generous, perhaps to a fault. I am fully aware, however, that their expressions of commendation are not necessarily to be talien as complete adherence to the views I have set forth. 
been better or more clearly phrased, because some reviewers understood me to say things which $I$ was astonished to find imputed to me and for which, with dae diligence, I can discover no basis in the text. When I re-read what I then wrote, I think I can detach a few concepts more general than most of the others, which for that reason I might call "basic" and which it may not be inappropriate to list here. They are the following:

1. Law is not a system of rules governing human conduct. Such systems are the proper field of religion, ethics, economics, politics, sociology and all other disciplines which consciously or unconsciously value some examples of human behavior as better or worse than others.

2. Law, therefore, has no real subject matter of its own except its own procedure which assumes an independent value when, as has been the case in most western states, law has become the special interest of a group, more or less self-perpetuating, consisting of technicians who develop a special terminology of their own of which they are extremely jealous.

3. Law is the sum total of the generalizations derived from judgments that a definite group of public officials, generally judges or persons like judges, have made or are likely to make about human behavior. These judgments are mediately or immediately derived from the values created by these other disciplines. They are miscellaneous, casual, historically determined, inevitably contradictory and can only very imperfectly be arranged under large generalizations, whether these generalizations are called "principles" or "rules".

4. These generalizations imperfect, as they are, even so far as the field of legal judgments is concerned, and subject, as they are, to changes by inclusion and exclusion, are sufficiently stable in any "system of law" to be the means of studying and expounding "the law" and of justifying new judgments according to the ease with which they can be fitted into the established generalization.

5. This latter fact is not of itself regarded as a sufficient justification for the judgment although it furnishes a basis of choice when several judgments, all equally valid by the standards mentioned, are possible.

6. Legal judgments may exist - indeed, must exist - in communities which have not, like most Western States, segregated a group of judge-officials whose exclusive task it is to form such judgments. In such communities it is often difficult to distinguish legal from political, social and ethical judgments. 
7. Nonetheless, the distinction can with greater or less difficulty be made in all communities. In Western communities, also, the segregation of judicial officials is a comparatively recent historical development and has never been absolute. Many legal judgments have been continued from a pre-differentiated stage in the community's growth when they could have been called ethical and social as much as legal.

8. Any particular legal judgment is phrased in terms of greater or less generality. It is derived, however, from an actual or conjectural decision in a specific case in which an individual and unique claim is granted or denied. Some method of legal analysis is useful for stating the presence or absence of a claim and for brealing up the general terms used into their constituent parts.

9. "The law" as a generalization of legal judgments is always incomplete since it is always concerned with a specific question not yet decided, as well as thousands already decided. The prognosis of that decision involves an estimate in advance of the factors that will determine the future judgment. In spite of the possible variety and number of these factors, the advance estimate is so highly probable in a number of cases that the statement of the law can be made with a fair degree of certainty and precision, and no decision will be required to test its accuracy since most men will regard the decision as a foregone conclusion.

10. Decisions will consequently be called for chiefly in what may be called marginal cases, in which prognosis is difficult and uncertain. It is this fact that makes the entire body of legal judgments seem less stable than it really is.

11. The determining time of judgments has nearly always been the time at which the conflict of interests occurred which called for judicial decision. This time is necessarily a past time and the complete reconstruction of this past time, upon which the decision must be based, is an obvious impossibility. The reconstruction can, of course, be approximated but to a large extent is artificial and is often created out of general patterns derived from recorded experience.

12. It is possible in some cases to disregard the past element and base the decision on a desirable prospective reorganization of the relations of the parties affected, whether they are litigants or not. That is the situation in certain types of judgments in which large groups of commercial interests are simultaneously involved, as in corporate reorganization, and also in cases in which economic groups are in conflict, as in labor cases. 
13. It is very doubtful whether this method can be generally extended to conflicts between individuals, since the prospective reorganization demands the application of a scale of values less likely to be generally acceptable than those used in order to redress past wrongs.

14. The one value that can never be quite disregarded in any legal judgment is the one based on an accepted sense of justice. That the components of this sense of justice vary greatly in space and time is demonstrable. But it is also demonstrable that, for types of developed societies during a period of many centuries, some of these constituents have been permanent.

15. Of these permanent constituents the notion that each human being is an end in himself, as expressed in the Kantian formula, is perhaps the one most likely to be the nucleus of any re-adaptation of the sense of justice to economic and social changes. Out of it the values symbolized by the words liberty and brotherhood can, I think, most readily develop.

16. In any body of legal judgments, a revaluation in terms of justice is from time to time inevitable. But the fact that the application of legal judgments is often entrusted to an institttionalized body of expert technicians makes it likely that the revaluation will be attempted only when conformity to a traditional set of generalizations leads to results widely divergent from the accepted sense of justice, either in its permanent elements or in some of the more striking ones created by special circumstances of time and place.

All this I thought I had said in "The Law as Logic and Experience". The manner was less solemn than in the sixteen paragraphs that have just preceded, which can be made fifteen or three or seven by anyone who prefers these numbers. And the illustrations I selected were sometimes not as dignified as they ought to have been. For both these errors, a now incurable tendency to frivolity is responsible. I stressed particularly the fact that any system of law in a complex community was the historical resultant of many special and disparate developments, and that organs devised for different things often came to be associated and fused with those which lawyers used in order to test and declare legal judgments. There is no reason in the world why the same methods and terms should be used in keeping order and in adjusting family relations, as in securing payment for the delivery of goods. It is an historical accident that it is so managed in our community. A better acquaintance with history would make it clear to us when we are utilizing social mechanisms for the things they were originally meant to do 
and when we are attempting to do something these social mechanisms can accomplish only clumsily and imperfectly. Sometimes we have the distinct impression that we are cutting silk with a saw or plowing with a sword.

But everything the court does emerges as law, and the rationalizations and generalizations of the judgments the court announces take their place in the body of "the law" and make it a system - although only at the cost of a deal of modelling, fitting, adjusting and completing.

A statement like this leaves out a great many things, even many of the things I have discussed in the book I mentioned, which is itself little more than an essay or a group of short related essays. Can it be called "realism"? Professor Hall doubts it, since he thinks my conclusion makes of me an "alleged" realist. ${ }^{3}$ I doubt it equally, not quite for his reasons. The term "realist" has been used in politics in the evil sense of a theory that any policy is defensible which secures political advantage both among nations and among groups within nations. Similarly there are lawyers - chiefly those who regard themselves as opponents of "realism" - who think that the realist position requires judgments to be based exclusively on a consideration of the economic advantages of the litigants or the groups to which they belong. This cannot be fairly said of such realists as Bingham and Llewellyn. And in any case, I do not maintain it.

Realism proper, I should say, is a method of looking at the law with the conviction that law directly concerns human beings, complete physical human beings, not parts or aspects of them, not bundles of rights and not abstract formulations however noble and inspiring. But a complete human being is one who is likely to love liberty and his fellow-man, to dream dreams and see visions, as well as one that prefers cake to bread, or is wholly intent on making a substantial income by his labors.

Nor does realism ignore the function of reason - even in the form of the decried syllogism - in making it possible to understand the law and communicate it. Man happens to be the kind of creature who is logical when he reflects on what he has done, even if he is not always so when he acts. And realism equally does not ignore the aesthetic qualities of an "elegant solution", which have more than once turned the scale when several judgments could be equally grounded in the body of accepted values. The living human being is fearfully and wonderfully made and his constituent elements are not wholly digestive juices and blood corpuscles.

I hope I can justify my right to be called a realist in this sense, but I should have to bear with equanimity a sentence of excommunication by real realists if this profession of faith seems to them evidence

3. Hall, review of Radin, LAw as Logic and Expesuence (1940) in (1941) 26 IowA L. Rev. 915-918. 
of damnable heresy. I do not mind being called a naive realist, to use Professor Patterson's words, since even he is willing to. believe that labels are not important. ${ }^{4}$

Professor Hall holds it against me that I make law wholly a matter of language, so that lawyers become merely philologists, expert in the use of that language. Well, if it were so, lawyers would have themselves to thank for it, and I think it is so to the extent that no professional group can avoid a technical terminology. But I hoped I had made plain that it was of the essence of legal science to understand the limitation of terminology and to avoid taking any term to be a fixed and rigid constant composed of atomic invariables. If lawyers were really philologists, they would be less afraid of the words they had created for their convenience of intercommunication, and be less likely to fall down and worship their handiwork.

But I suppose what Professor Hall chiefly objects to is my disinclination to take the law as a coherent body of rational principles which, as such, can direct our actions. The only possible plea I can enter is one of confession and avoidance.

I am not as much impressed as I should be by the fact that an eminent Freudian like Dr. Franz Alexander thinks that the facts of psychoanalysis show rationality and benevolence as much as irrationality. I am inclined to trust my own observation of human conduct - if I said "behavior", I should be hanged as a Watsonian - more than the conclusions of psycho-analysts, older or newer. And if this observation seems to show that the majority of our actions are, for the most part, not the results of rational consideration but are instinctive or habitual, it doubtless proves that I have not met the right sort of people. But I have seen a great many. By "irrational", of course, I do not mean foolish or malevolent. Speaking as an Aristotelian, I make bold to say that the confusion of contradictories and contraries has done serious harm to law.

When I read Dr. Aronson's review of the volume in question, ${ }^{\circ} \mathrm{I}$ have the puzzled feeling that he cannot quite be speaking of that book, but of a book I should have written if I had been a consistent empiricist or hedonist - he believes me to profess either or both doctrines. Where in the book do I speak of a "'pleasure-theory' of justice"? Doubtless

4. Quoted by Professor Hall, id. at 916.

5. Professor Patterson's review appeared in (1941) 41 Cot. L. Rev. 562-566. One cannot escape the impression that labels mean more to Professor Patterson than he consciously admits. Otherwise it is hard to see why he makes a list of these entertaining devices while professing to disdain them. The grammarians called this "preterition". Shall we say that Professor Patterson is the head of the preteritional school?

6. Aronson, review of RAdin, LAw as LoGic and Experience (1940) in (1941) 20 TEX. L. REv. 118-125.

7. Id. at 124. 
I do, since Dr. Aronson found it there, but my own researches have been less successful. And since the experience to which I refer is, by definition and frequent illustration, an experience that has filtered through generations and is checked by critical examination, and is never the experience of one man, I do not feel that the charge that I am guilty of a sort of inverted subjectivism is overwhelmingly established.

About inconsistency I will not quarrel with $\mathrm{Dr}$. Aronson. He quotes a passage, which I think is quite correctly taken as characteristic, in which I decline to find a single formula, a single right method, a single key for the law. "What is sauce for the goose," he says, "is decidedly not sauce for the gander in this philosophy." 8 Quite so. It is not even necessarily sauce for geese. So, while I think present-day police and judges are less competent persons than present-day criminologists to deal with criminals - I am enough of a Lombrosian to prefer to be concerned with the delinquente than the delitto - I still think presentday judges are more competent than present-day criminologists to determine whether or not a man is a criminal. Whether that will be so when judges become philosophers or scientists become aware of the meaning of the Bill of Rights, I do not know.

Since I painfully explain that the same legal mechanism is called upon to apply values of widely different sources, I am at a loss to know what inconsistency there is in saying that matters of different origin are not made generically alike by being placed in the same field of operation. But Dr. Aronson is a consistent idealist which means, I suppose, that he has direct acquaintance with certain entities like right and wrong, and that he strongly feels, once these are examined, a consistent method of dealing with conduct is obtainable.

I hope I have never said that ideas like wrong and right, or any ideas, are worthless or meaningless terms. Or even that in any one generation or community they are altogether fluid and shifting. I do nonetheless feel that they are human expressions, suggestive and directive rather than solid creations. I can easily understand that, to those who move easily among archetypes, examination of human values that are colored and shaded by human wants and human needs is trivial and dispiriting. It is, however, the best that doctrines like the ones I advocate permit.

Dr. Felix Cohen ${ }^{9}$ is both a logician and a lawyer and brings to any study a combination of talents that would be hard to surpass. If I say I do not think he has quite got what I meant to set forth, I am more than willing to feel that the fault is mine. Dr. Cohen is strongly of the opinion that law is more than "a mode of judicial dealing with contracts, collisions and homicides". I cannot imagine any one contradicting this

8. Ibid.

9. Dr. Felix S. Cohen's review appeared in (1941) 54 Hanv. L. Rev. 711-714. 
self-evident assertion. Indeed, my complaint is that our judicial mechanism deals with rather too many than with too few forms of conflict. The point, labored somewhat at large in the text, is that the conflicts are not the substance of the law but tests for determining what the law is. If no one had ever broken through another's close, we should not know the extent and limitation of the right of an owner to exclude others. The various instances, as they happened, got rationalized and organized into a statement of the law on the subject. It would be quite incorrect to say that physics is a scientific way of dealing with experiments, but quite correct to say that from the experiments we determine what the laws are that in their sum constitute physics.

The difference between law and physics is that the "laws of physics" when discovered are likely to be fairly permanent, while the law which is worked out by generalizations from the legal experimentation involved in adjusting conflicts by means of courts has only a limited permanence for some of the elements in its complex constitution and even this limited permanence is subject to gradual modifications.

This is fundamental in the approach to law that I meant to present and Dr. Cohen's misunderstanding of it is regrettable. Equally regrettable is the misunderstanding of what is set forth in the book as the function of law. He quotes the statement that "To secure a good society . . . cannot be the purpose of law for the simple reason that it is the purpose of the entire mechanism of political and social organs." And he goes on to say: "Unfortunately, we are not told why law may not pursue a purpose to which other institutions are also dedicated." We could not be told so because clearly law may and does pursue such a purpose. Since law is part of the entire mechanism, this is precisely what the sentence says. If Dr. Cohen will read a little further down on the page he cited, he will discover this fact, if the obvious meaning of the sentence did not tell him. What is denied is that this purpose can possibly be the peculiar task of the law, since it is also the task of other agencies. Shall we call it a lapse on the part of an eminent logician into the fallacy of division?

Dr. Cohen likewise stops too soon in the passage he quotes more fully from page 146:

"Not justice or a good society, therefore, but convenience of commercial practice, appeasement of individual quarrels, or an increase of good will among competitors, if that is possible, is the purpose of law if we examine its actual operation."

His comment is that the list is far too narrow. It is, indeed, if this was to be taken as a full statement. How little it was intended to be an exhaustive statement of the purposes of law can be seen from the next sentence which runs as follows: "And to these three purposes other 
purposes can be added, such as the direction of the domestic policies of the country in constitutional questions or the elimination of non-offenders from the group of punishable persons." The "such as", I trust, saves even these additions from pretending to be a final complement. If all together these things still make my outlook seem narrow and inadequate to Dr. Cohen - how it can be irrelevant is not altogether clear - this can easily be remedied by adding any purpose Dr. Cohen chooses, provided it can be illustrated by a possible conflict of interests between human beings. ${ }^{10}$

I am somewhat disturbed to find the book described as a "trumynt call for a retreat from the intellectual outposts of legal reform". That is so extraordinary a charge in view of the whole tenor of the buok that I can only assume it is due to inadvertence. I have suggested throughout, and especially in Part III (pages 64 et seq.), lines of development that were, I imagined, far-reaching enough. But after all, the main purpose of an exposition-quite undogmatic in spite of Dr. Cohen's statement to the contrary - is surely not to plead for a reform, either a general reform or a particular one. It may be, however, that every effort to reform human institutions is slightly aided by those who attempt merely to clarify our notions about what it is that is to he reformed. ${ }^{11}$

I have dealt fully with these three reviews because all three contain implicitly the notion that principles of law, or a principle of law, exist independently of legal judgments and determine these judgments; for example that neminem laedere created a law of torts and summ cuique a law of property. That is the real issue, even in the case of Dr. Cohen's criticism, since, somewhat curiously in view of what he has written elsewhere, he likewise makes of "The Law" almost a being with organs and dimensions.

10. Dr. Cohen thinks it is my purpose to eliminate "the piffling particularity of an ephemeral statute" (p. 5). I shall let him into a secret. The phrase was meant jocosely. And I trust that he means to be jocose when he speals of an assumption on my part to offer eternal wisdom to a waiting world. I cannot see what word or phrace in anything I have ever written can possibly lend itself to such an interpretation.

11. I find it difficult to connect what Dr. Cohen has to say about criminal law with what I say about it. Doubtless in Athens and to a less degree in Rome the only difference between what we now call criminal and civil suits was a matter of procesure But criminal law at the present time means a device for determining what persons are to be segregated or killed in the interests of social security. That is more than a progedural matter. When Dr. Cohen asks, "What would rules and dccisions concerning property mean if criminal penalties could not be invoked at some stage in their enforeement?", the answer is of course that they would mean that in the particular community in question - there have been such communities - those who disregarded the duty of not meddling with the property of other persons were not punished by state agencie: It certainly would not mean the absence of a strong feeling and a precise sents of the value of property. 
Principles of law are undoubted facts, but they are constantly in a state of growth and they come into existence after longer or shorter application of individual habits of judgment. They are compacted of notions of ethical right, religious obligation, practical utility, logical coherence and, often enough, more or less conscious feeling of group solidarity. The same principle repeated verbatim in different generations is found on analysis to be composed of these elements and others in different proportions. Once such a composite is phrased in words, however, and is used by a specialized group of technicians, logical coherence is far too often granted a greater value than other elements in it, and it becomes a detached and disembodied entity that is readily referrecl back in time to the beginning of things.

All the principles taken together cannot be reduced to a single system, even if we forego mathematical precision. What makes them principles of law rather than principles of sociology or any other science, is that a special group of technicians have developed and asserted them. This special group is itself of multiple origin and carries into its law function many of the impulses and purposes it had in the other function with which some or all its members were entrusted.

Those to whom a coherent system is an indispensable way of understanding the law properly take issue with the book I am here attempting to defend. Its errors and imperfections are many. Most of them are due to the fact that almost any sentence about social institutions indeed, about human beings - is bound to need qualifications. It is not enough to make the qualifications clear in one particular passage. When the words are used again, they are likely to be taken unqualifiedly by readers who cannot reasonably be expected to deal with ordinary books as they would with - let us say - Kant's Critiques or the Origin of Species.

Most of those who have found it necessary to render an adverse judgment on the book have done so in a frame of courteous compliments. Their right to disagree with the ideas set forth is protected by the Fifth and Fourteenth Amendments from interference by the Federal or the State governments. It is gratifying that there have been so many reviews and that to many scholarly and thoughtful lawyers a review of a book like this has been the occasion of announcing a theory of their own.

I have a distinct feeling that even in subsequent volumes of the Storrs lectures the last word will not have been said about the nature and function of law. I feel sure that at all times there will be men who find law to be the logical consummation of a doctrine that can be reduced to a single principle capable of being stated in phrases bristling with large, comfortable and abstract words. There is no combination of abstractions out of which a good Hegelian could not make something - at the very least, a theory of law. 
And I trust there will also always be on hand some who will seek to find law in the expressed judgments of men who have most to do with it, especially when in any community these men are formally entrusted with the task of dealing with law. Once we begin with men, we may end in the broadest generalizations - abstract in the sense that they have been taken from actual experience, but not abstract in the sense of being removed so far from experience that they have lost the recollection of their source.

The generalizations will, I think, be all the better if those who use them are conscious of their tentative character and conscious also that they are speaking in the last analysis of creatures that have emotional and spiritual needs as well as physical. 